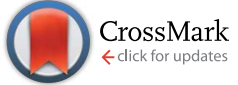

Cite this: RSC Adv., 2016, 6, 107717

Received 22nd August 2016

Accepted 3rd November 2016

DOI: $10.1039 / c 6 r a 21059 g$

www.rsc.org/advances

\section{One-step fabrication of high quantum yield sulfur- and nitrogen-doped carbon dots for sensitive and selective detection of $\mathrm{Cr}(\mathrm{vI}) \dagger$}

\begin{abstract}
Saihua Wang, ${ }^{\text {ab }}$ Hongyun Niu, ${ }^{* a}$ Sijing $\mathrm{He}^{\mathrm{a}}$ and Yaqi Cai ${ }^{\mathrm{a}}$
In this work, we have developed a green, simple, and low-cost hydrothermal method using wool and pig hair as the precursor to fabricate sulfur- and nitrogen-doped carbon dots (CDs). The precursors are natural and nontoxic raw materials, and the one-step strategy requires no organic solvents. The asprepared carbon dots exhibit good water dispersibility, strong fluorescence emission with a relatively high quantum yield of $25.6 \%$ (contributed by the doped $\mathrm{N}$ and $\mathrm{S}$ elements), excellent $\mathrm{pH}$ stabilities and high ionic strength tolerance. More importantly, the fluorescence intensity of the CDs could be significantly and selectively quenched in the presence of $\mathrm{Cr}(\mathrm{vI})$ due to the oxidation-reduction reaction between $\mathrm{Cr}(\mathrm{VI})$ and the oxygen-containing groups and S-related species on the surface of CDs. Accordingly, the CDs are employed as a fluorescent probe for the detection of $\mathrm{Cr}(\mathrm{vI})$ ions in water. This CDs sensor exhibits high sensitivity to $\mathrm{Cr}(\mathrm{Vl})$ with a limit of detection of $16.8 \mathrm{nM}$ in a wide range of $50 \mathrm{nM}$ to $100 \mu \mathrm{M}$. Furthermore, the sensor is successfully applied in the detection of $\mathrm{Cr}(\mathrm{VI})$ in real water samples.
\end{abstract}

\section{Introduction}

Chromium is one of the major water pollutants due to its widespread use in modern industries, including leather tanning, electroplating and wood preservation. Consequently, chromium has inevitably led to serious threats to the environment and human health. $\mathrm{Cr}(\mathrm{vI})$ is most hazardous because of its highly carcinogenic and mutagenic properties. ${ }^{1}$ So, an accurate and reliable method for the determination of $\mathrm{Cr}(\mathrm{vI})$ is in great demand. Until now, numerous analytical techniques, including chromatography, ${ }^{2}$ spectrophotometry, ${ }^{3}$ electrochemical techniques $^{4}$ and atomic absorption spectrometry, ${ }^{5}$ have been developed for the direct assay of $\mathrm{Cr}(\mathrm{vI})$ ions. However, most of these techniques require expensive equipment and complicated pretreatment steps. Therefore, spectrophotometry with fluorescent probes has been a great alternative for its quick, simple and highly sensitive properties. But the fluorescent probes used to detect $\mathrm{Cr}(\mathrm{vI})$ in previous reports always are small organic dyes, ${ }^{3}$ organic nanoparticles, ${ }^{6}$ or semiconductor quantum dots, ${ }^{7}$ which have intrinsic limitation, such as low sensitivity, photobleaching effect, broad emission bands and biotoxicity.

Carbon dots (CDs), a new member of carbon nanomaterials, have remarkable advantage in high resistance to photobleaching,

${ }^{a}$ State Key Laboratory of Environmental Chemistry, Ecotoxicology of Research Center for Eco-Environmental Sciences, Chinese Academy of Sciences, Beijing 100085, China. E-mail: hyniu@rcees.ac.cn

${ }^{b}$ University of Chinese Academy of Sciences, Beijing, 100049, China

† Electronic supplementary information (ESI) available. See DOI: 10.1039/c6ra21059g robust chemical inertness, high sensitivity, low toxicity and good biocompatibility. ${ }^{8-11}$ Due to the outstanding properties, CDs have been used as fluorescent probes for the trace analysis of metal ions (such as $\mathrm{Fe}^{3+}, \mathrm{Hg}^{2+}, \mathrm{Cu}^{2+}$ and $\mathrm{Ag}^{+}$, etc.), ${ }^{12-17}$ and some organic compounds (such as glucose, DNA, vitamin B12, and dopamine, etc.). ${ }^{18-21}$ Recently, graphene quantum dot membrane, ${ }^{22}$ boron and nitrogen co-doped carbon dots, ${ }^{23}$ cobalt(II)-doped carbon dots ${ }^{24}$ and phosphate functionalized carbon $\operatorname{dots}^{25}$ have all been successfully employed as probes for the determination of $\operatorname{Cr}(\mathrm{vI})$. But as far as we know, the fluorescent probes for $\mathrm{Cr}(\mathrm{VI})$ in previous reports have involved organic reagent, complex process and severe synthetic conditions. The desire for novel and simple methods to fabricate sulfur and nitrogen co-doped CDs which are highly sensitive for the detection of $\mathrm{Cr}(\mathrm{VI})$ ions is still challenging.

To overcome these shortcomings, several researchers have devoted to the exploring of new green and simple methods without the use of organic chemicals in recent years. Among them, green synthetic approaches using cheap and eco-friendly biomass directly from nature such as green tea, ${ }^{26}$ milk, ${ }^{27}$ garlic, ${ }^{28}$ soya bean, ${ }^{29}$ watermelon pee ${ }^{30}$ and honey ${ }^{31}$ as the precursors to produce CDs are very promising solutions and have drawn a great deal of attention. However, the reported CDs derived from natural plant precursor abundant in saccharide usually have either low quantum yield (QY) or low pH stabilities, which limit their application in environmental analysis. Therefore, it is highly desirable to explore a new carbon source for the economical and green synthesis of efficient fluorescent CDs.

Recently, Hou applied a hydrothermal method to prepare CDs with human hair, mainly consisting of carbon, oxygen and nitrogen owing to the large amount of keratin, as precursor. The 
obtained CDs exhibited strong and stable PL, which is dependent on excitation wavelength and $\mathrm{pH}$, high quantum yield, and high sensitivity and good selectivity to the determination of $\mathrm{Hg}^{2+} \cdot{ }^{12} \mathrm{Zhu}$ developed a novel one-step approach for the largescale synthesis of sulfur- and nitrogen-co-doped carbon dots (S-N-C-dots) with tunable luminescence properties by using sulfuric acid carbonization and etching of hair fiber. ${ }^{32}$ In the present study, the nature precursors for CDs were expanded to animal hair (wool and pig hair), which are much cheaper and less influenced by chemicals like shampoos, hair dyes and so on. The synthesis method has the advantage of green, simple and low cost. The achieved CDs are rich in sulfur and nitrogen elements, and possess good water dispersibility, strong fluorescence emission, brilliant $\mathrm{pH}$ stabilities and high ionic strength tolerance. Most importantly, the as-synthesized CDs exhibit excellent selectivity to $\mathrm{Cr}(\mathrm{vI})$.

\section{Experimental section}

\section{Materials}

The wool and pig hair were collected from a farm. $\mathrm{K}_{2} \mathrm{Cr}_{2} \mathrm{O}_{7}$, $\mathrm{K}_{2} \mathrm{CrO}_{4}, \mathrm{NaCl}, \mathrm{KCl}, \mathrm{AgNO}_{3}, \mathrm{MgCl}_{2} \cdot 6 \mathrm{H}_{2} \mathrm{O}, \mathrm{MnCl}_{2} \cdot 4 \mathrm{H}_{2} \mathrm{O}, \mathrm{CaCl}_{2}$, $\mathrm{FeCl}_{2} \cdot 4 \mathrm{H}_{2} \mathrm{O}, \mathrm{FeCl}_{3} \cdot 6 \mathrm{H}_{2} \mathrm{O}, \mathrm{BaCl}_{2} \cdot 2 \mathrm{H}_{2} \mathrm{O}, \mathrm{CoCl}_{2} \cdot 6 \mathrm{H}_{2} \mathrm{O}, \mathrm{Cu}\left(\mathrm{NO}_{3}\right)_{2}-$ $\cdot 3 \mathrm{H}_{2} \mathrm{O}, \mathrm{Hg}\left(\mathrm{NO}_{3}\right)_{2}, \mathrm{~Pb}\left(\mathrm{NO}_{3}\right)_{2}, \mathrm{CrCl}_{3}, \mathrm{Zn}(\mathrm{Ac})_{2} \cdot 2 \mathrm{H}_{2} \mathrm{O}, \mathrm{CdCl}_{3} \cdot 6 \mathrm{H}_{2} \mathrm{O}$, $\mathrm{NaClO}_{4}, \mathrm{NaBr}, \mathrm{Na}_{2} \mathrm{SO}_{4}, \mathrm{KH}_{2} \mathrm{PO}_{4}$, EDTA and KSCN were purchased from Sinopharm Chemical Reagent Co., Ltd (China). Quinine sulfate dihydrate $\left(\left(\mathrm{C}_{20} \mathrm{H}_{24} \mathrm{~N}_{2} \mathrm{O}_{2}\right)_{2} \cdot \mathrm{H}_{2} \mathrm{SO}_{4} \cdot 2 \mathrm{H}_{2} \mathrm{O}\right)$ was obtained from J\&K Chemicals Ltd. (Beijing, China). All chemicals were of analytical reagent grade and used without further purification. Ultrapure water was prepared in the lab using a Milli-Q SP reagent water system (Millipore, Bedford, MA, USA).

\section{Instruments and characterizations}

The fluorescence (FL) and the UV-vis absorption spectra were performed with a Hitachi F-4600 fluorescence spectrophotometer and Hitachi UV-2910 spectrophotometer, respectively. A JEM-2100 field-emission transmission electron microscopy (JEOL, Japan) was used to characterize the morphology of the asprepared CDs. The crystal structure was obtained by X-ray diffraction (XRD, PAN-alytical X'Pert diffractometer, Almelo, Netherlands) using a monochromatized X-ray beam with nickelfiltered $\mathrm{Cu} \mathrm{K} \alpha$ radiation and $4^{\circ} \mathrm{min}^{-1}$ scan rate. Fourier transform infrared (FTIR) spectra were recorded using KBr pressed pellets on a NEXUS 670 Infrared Fourier Transform spectrometer (Nicolet Thermo, USA). X-ray photoelectron spectroscopy (XPS) measurements were conducted by applying a Thermo Scientific ESCA-LAB-200i-XL spectrometer (Waltham, MA) with monochromatic $\mathrm{Al} \mathrm{K} \alpha$ radiation $(1486.6 \mathrm{eV})$.

\section{Synthesis of the carbon dots}

The carbon dots were synthesized using a hydrothermal carbonization method. The wool and pig hair were firstly washed with cleanser essence and distilled water thoroughly, cut into small pieces ( $\sim 5 \mathrm{~mm}$-in-length), and dried in oven. Then $0.5 \mathrm{~g}$ prepared fibers and $10 \mathrm{~mL}$ ultrapure water were transferred into a $25 \mathrm{~mL}$ Teflon-lined stainless steel autoclave, heated at $240{ }^{\circ} \mathrm{C}$ for $6 \mathrm{~h}$, and cooled to room temperature naturally. Next, the aqueous solution was filtered through a 0.22 $\mu \mathrm{m}$ membrane and centrifuged at $12000 \mathrm{rpm}$ for $10 \mathrm{~min}$ to discard the non-fluorescent deposits. The bright yellow CDs aqueous solution was collected and further dialyzed in a dialysis bag (molecular weight cutoff $=1000 \mathrm{Da}$ ) for $24 \mathrm{~h}$. The purified CDs were preserved at $4{ }^{\circ} \mathrm{C}$ for further use. The CDs prepared from wool and pig hair are named as W-CDs and P-CDs, respectively.

\section{Fluorescence detection of $\mathrm{Cr}(\mathrm{vI})$ ions}

For a typical assay, $3 \mu \mathrm{L}$ of CDs, followed by the addition of different concentrations of $\mathrm{Cr}(\mathrm{vI})$ ions, were diluted to $1 \mathrm{~mL}$ with deionized water by a vortex mixer for a few seconds. The mixtures were equilibrated at room temperature for $20 \mathrm{~min}$ before the FL spectroscopy measurements were recorded. The resulting solutions were measured by FL spectroscopy at room temperature with an excitation at $350 \mathrm{~nm}$, both the excitation and emission slit were $3 \mathrm{~nm}$.

\section{Selectivity measurements}

To examine the selectivity of CDs to the Cr(vI) anions, a series of competitive metal ions and anions, including $\mathrm{Na}^{+}, \mathrm{Ca}^{2+}, \mathrm{Cd}^{2+}$, $\mathrm{Cr}^{3+}, \mathrm{K}^{+}, \mathrm{Fe}^{3+}, \mathrm{Fe}^{2+}, \mathrm{Ag}^{+}, \mathrm{Mg}^{2+}, \mathrm{Ba}^{2+}, \mathrm{Zn}^{2+}, \mathrm{Cu}^{2+}, \mathrm{Pb}^{2+}, \mathrm{Mn}^{2+}, \mathrm{Co}^{2+}$, $\mathrm{Hg}^{2+}, \mathrm{Cl}^{-}, \mathrm{Br}^{-}, \mathrm{SO}_{4}{ }^{2-}, \mathrm{H}_{2} \mathrm{PO}_{4}{ }^{-}, \mathrm{Ac}^{-}$and $\mathrm{ClO}_{4}{ }^{-}$were mixed with $3 \mu \mathrm{L}$ of CDs by a vortex mixer under the same conditions. The concentration of $\mathrm{Cr}(\mathrm{vI})$ ions and other interference ions were $500 \mu \mathrm{M}$. The resulting solutions were measured by FL spectroscopy at room temperature with excitation at $350 \mathrm{~nm}$, both the excitation and emission slit widths were $3 \mathrm{~nm}$.

\section{Real samples}

Three types of environmental water samples, namely lake water sample, tap water sample and river water sample, were used to evaluate the effect of sample matrix on $\mathrm{Cr}(\mathrm{vI})$ detection. The lake water sample was acquired from Gaobeidian Lake, Beijing, China. The river sample was collected in Xiaoyue River, Beijing, China. The tap water sample was taken from our laboratory in Haidian District, Beijing. All samples were collected randomly and filtered through $0.22 \mu \mathrm{m}$ nylon membranes to remove suspended particles. The filtered water samples were analyzed within $24 \mathrm{~h}$.

\section{Results and discussion}

\section{Optimization of synthesis conditions}

As the fluorescent behavior of the carbon dots is affected by the mass of the precursor, the temperature and time of the hydrothermal process, it's necessary to optimize the experimental conditions in order to achieve carbon dots with the best fluorescence properties. As showed in Fig. S1A, $\uparrow$ the FL QY of W-CDS increased with the increase of wool mass in the precursor solution ( $10 \mathrm{~mL}$ ultrapure water) ranging in 0.1 to $0.5 \mathrm{~g}$ and then decreased as the wool mass in the precursor solution went over $0.5 \mathrm{~g}$. So the wool mass was fixed at $0.5 \mathrm{~g}$, then the effect of temperature was investigated. The result clearly demonstrated 
that the FL QY of W-CDs increased gradually with the temperature and obtained the highest QY at $240{ }^{\circ} \mathrm{C}$ (Fig. S1B). $\dagger$ According to the Fig. S1C, $\uparrow$ the FL QY of W-CDs increased with the increase of reaction time up to $6 \mathrm{~h}$ and decreased in the period from 6 to $12 \mathrm{~h}$. In summary, the optimum experimental conditions are as follows: wool or pig hair mass $0.5 \mathrm{~g}$, reaction temperature $240{ }^{\circ} \mathrm{C}$ and reaction time $6 \mathrm{~h}$.

\section{Structure characterization}

The morphology and structure of the as-prepared fluorescent CDs were characterized by HRTEM. The as-prepared CDs have spherical shapes and are well dispersed in water solution (Fig. 1 and $\mathrm{S} 2 \dagger)$. Furthermore, well-defined lattice fringes are clearly observed (inset in Fig. 1A), with a lattice spacing of $0.20 \mathrm{~nm}$, corresponding to the (102) diffraction plane of graphitic $\left(\mathrm{sp}^{2}\right)$ carbon. As estimated from the HRTEM image, the W-CDs exhibited a narrow size distribution in the range of 4-8 nm with an average size of $5.9 \mathrm{~nm}$ (Fig. 1B). The XRD pattern of $\mathrm{W}$ CDs displayed a broader (002) peak centered at around $24.5^{\circ}$, which further confirmed the graphene structure of the W-CDs (Fig. S3A $\dagger$ ).

The chemical structure of CDs was further characterized by $\mathrm{X}$-ray photoelectron spectroscopy (XPS). In Fig. S3B, $\dagger$ the chemical compositions of $\mathrm{W}$-CDs consisted of $\mathrm{C}, \mathrm{O}, \mathrm{N}$ and $\mathrm{S}$, and the contents of these atoms were 62.54, 23.05, 13.66 and $0.75 \%$, respectively. The high resolution $\mathrm{C} 1 \mathrm{~s}, \mathrm{O} 1 \mathrm{~s}, \mathrm{~N} 1 \mathrm{~s}$ and $\mathrm{S}$ 2 p XPS spectra were shown in Fig. 2. The $\mathrm{C} 1 \mathrm{~s}$ spectrum can be resolved as follows: $\mathrm{C}-\mathrm{C}$ and $\mathrm{C}=\mathrm{C}$ at $284.4 \mathrm{eV}, \mathrm{C}-\mathrm{S}$ at $285.4 \mathrm{eV}$, $\mathrm{C}-\mathrm{N}$ at $286.3 \mathrm{eV}$, and $\mathrm{C}=\mathrm{O}$ at $287.9 \mathrm{eV}$. The three fitted peaks at $530.5,531.4$ and $532.5 \mathrm{eV}$ in $\mathrm{O} 1 \mathrm{~s}$ spectrum were assigned to $\mathrm{C}=$ $\mathrm{O}, \mathrm{C}-\mathrm{OH} / \mathrm{C}-\mathrm{O}-\mathrm{C}$ and $\mathrm{O}=\mathrm{C}-\mathrm{O}$ groups, respectively. The $\mathrm{N} 1 \mathrm{~s}$ peaks at 399.4, 400.0 and $401.1 \mathrm{eV}$ indicated that nitrogen existed mostly in the form of $\mathrm{C}-\mathrm{N}-\mathrm{C}, \mathrm{N}-\mathrm{C}_{3}$ and $\mathrm{N}-\mathrm{H}$, respectively. The $\mathrm{S} 2 \mathrm{p}$ spectrum consisted of two peaks, corresponding to $\mathrm{C}-\mathrm{S}-\mathrm{C}(163.6 \mathrm{eV})$ and $-\mathrm{C}-\mathrm{SO}_{x^{-}}(x=2,167.5 \mathrm{eV} ; x=3$, $168.4 \mathrm{eV}, x=4,169.1 \mathrm{eV})$, respectively. ${ }^{14}$ These indicated that the as-prepared W-CDs were rich in hydrophilic groups (hydroxyl, carbonyl, and carboxylic acid groups) on the surfaces. The presence of these functional groups endowed excellent solubility to the CDs in water without further chemical modification.

Meanwhile, the FTIR spectrum of CDs demonstrates the presence of the same groups as indicated by the XPS results (Fig. 3). The peak at $1135 \mathrm{~cm}^{-1}$ was ascribed to the $\mathrm{C}-\mathrm{O}$ and $\mathrm{C}-\mathrm{S}$ bonds. The peak at $1408 \mathrm{~cm}^{-1}$ can be ascribed to the $-\mathrm{COO}$ group while the peak at $1629 \mathrm{~cm}^{-1}$ was ascribed to the $\mathrm{C}=\mathrm{O}$
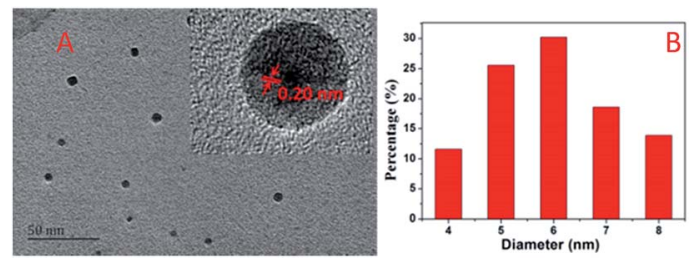

Fig. 1 HRTEM image (A) and the corresponding size distribution histograms (B) of the W-CDs.
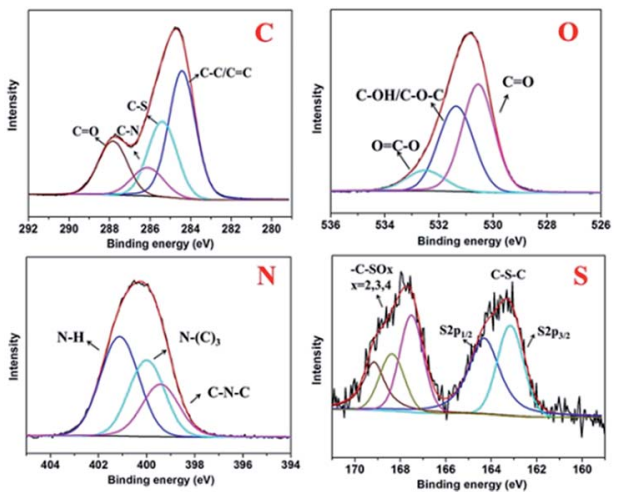

Fig. 2 High-resolution $C 1 s, O$ 1s, N 1s and S 2p XPS spectra of the WCDs.

stretching vibration and the peak at $2070 \mathrm{~cm}^{-1}$ was assigned to the $\mathrm{C}-\mathrm{N}$ group. In addition, the broad band at $3424 \mathrm{~cm}^{-1}$ corresponded to the stretching modes of $\mathrm{N}-\mathrm{H}$ and $\mathrm{O}-\mathrm{H}$. In short, these results confirmed that the obtained CDs are nitrogen-rich and sulfur-doped as expected.

\section{Optical characterization}

The optical properties of the CDs were studied using UV-vis absorption and photoluminescence spectroscopy. As presented in Fig. S4A, $\uparrow$ the resultant W-CDs displayed two typical UV-vis absorption peaks at $\sim 272$ and $340 \mathrm{~nm}$, respectively. The broad absorption peak around $272 \mathrm{~nm}$ was ascribed to the $\pi-\pi^{*}$ transition of aromatic $\mathrm{sp}^{2}$ domains, and the absorption peak centered at $340 \mathrm{~nm}$ indicated the presence of carbonyl or conjugated carbonyl groups. ${ }^{33}$ At the same time, the excitation and emission peaks appeared at $350 \mathrm{~nm}$ and $430 \mathrm{~nm}$, respectively. As illustrated in Fig. $\mathrm{S} 4 \mathrm{~B}, \dagger$ the emission from $\mathrm{W}$-CDS gradually shifted to higher wavelengths when the excitation wavelength increased from 300 to $400 \mathrm{~nm}$. The emission intensity increased when the excitation wavelength changed from 300 to $350 \mathrm{~nm}$ and then decreased gradually. This indicates the excitation-dependent emission behavior of W-CDs, which is one of the most special properties of carbon dots. The obtained W-CDs displayed narrow and symmetrical fluorescence spectra profiles, resulting from their narrower size distribution. Furthermore, the doping of $\mathrm{N}$ and $\mathrm{S}$ atoms significantly increased the quantum yield of the CDs, and the

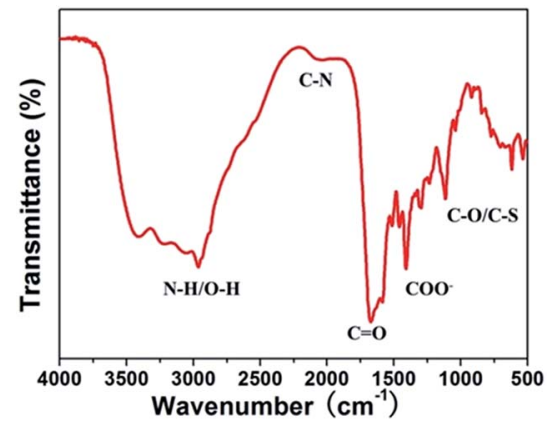

Fig. 3 FTIR spectrum of W-CDs. 
fluorescence quantum yield of W-CDs and P-CDs was calculated to be $25.6 \%$ and $20.1 \%$, respectively. As a result, the CDs were able to perform competently as a highly sensitive chemosensor.

The stability of CDs were investigated by measuring the FL intensity of the CDs under extreme $\mathrm{pH}$ and high ionic strength in solution. Fig. S5A $\dagger$ showed that the FL of the W-CDs at $430 \mathrm{~nm}$ upon excitation at $350 \mathrm{~nm}$ was strong and stable over a wide range of $\mathrm{pH}$ values $(\mathrm{pH} 2-10)$. As solution $\mathrm{pH}$ reached to 12 , the FL intensity was only decreased by $35 \%$. In the presence of different concentrations of $\mathrm{NaCl}$ (up to $1 \mathrm{M}$ ), the FL intensities remained constant with the increase of ionic strength, indicating the high stability of the W-CDs under a high ionic strength environment (Fig. S5B $\dagger$ ). Furthermore, the FL intensity had no obvious decrease as the sample was stored for over 60 days (Fig. S5C $\dagger$ ). Similar to the W-CDs, P-CDs also showed high $\mathrm{pH}$ stabilities and ionic strength tolerance. In conclusion, these finding suggested that the CDs were highly stable under extreme conditions and had great potential for sensing applications.

\section{Fluorescence response of CDs toward $\mathrm{Cr}(\mathrm{vI})$}

The as-prepared CDs were used to detect $\mathrm{Cr}(\mathrm{vI})$ in water. The $\mathrm{pH}$ value of the solution is an important factor that affects the quenching efficiency. There is no significant difference in the quenching efficiency $\left(F / F_{0}\right)$ in the presence of $\mathrm{Cr}(\mathrm{vI})$ in the range of $\mathrm{pH} 2-10$ (Fig. S6A $\dagger$ ). This indicates that the determination of $\mathrm{Cr}(\mathrm{vI})$ with CDs as fluorescent sensor is not $\mathrm{pH}$-dependent. In addition, the kinetic characteristics of the reaction system was investigated. The reaction was complete within $1 \mathrm{~min}$, and the stable fluorescent signal at $430 \mathrm{~nm}$ remained constant for at least $1 \mathrm{~h}$ (Fig. $\mathrm{S} 6 \mathrm{~B} \dagger$ ). Under the optimized conditions, the strong emission of the CDs could be quenched obviously when $\mathrm{Cr}(\mathrm{vI})$ ions were added into the solution. As shown in Fig. 4, upon the addition of $\mathrm{Cr}(\mathrm{vI})$, the fluorescence intensity at $430 \mathrm{~nm}$ decreased with the increase of the $\mathrm{Cr}(\mathrm{vI})$ concentration. There was a good linear relationship $\left(R^{2}=0.997\right)$ between the quenching efficiency $\left(F / F_{0}\right)$ and the concentration of $\mathrm{Cr}(\mathrm{vI})$ in the

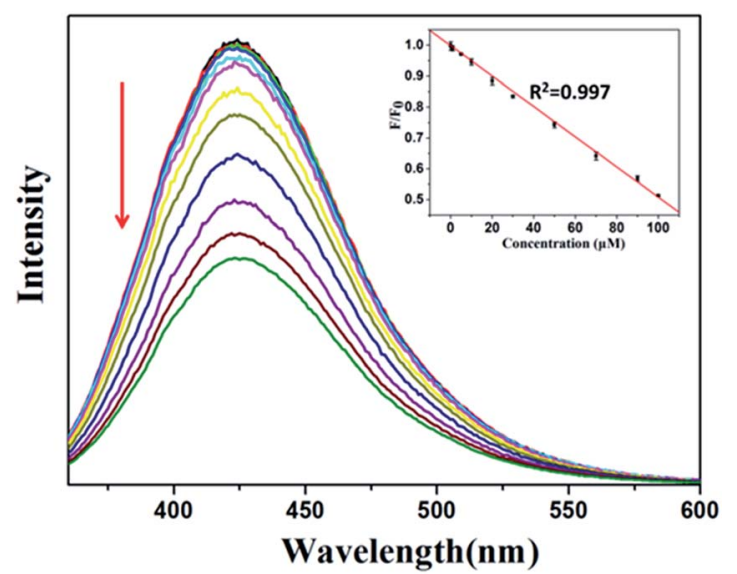

Fig. 4 Fluorescent emission spectra of W-CDs upon addition of various concentration of $\mathrm{Cr}(\mathrm{VI})$ (from top to bottom, 0, 0.05, 0.5, 1, 5, $10,20,30,50,70,90$ and $100 \mu \mathrm{M})$. Insets show the dependence of $F / F_{0}$ on the concentration of $\mathrm{Cr}(\mathrm{VI})$.

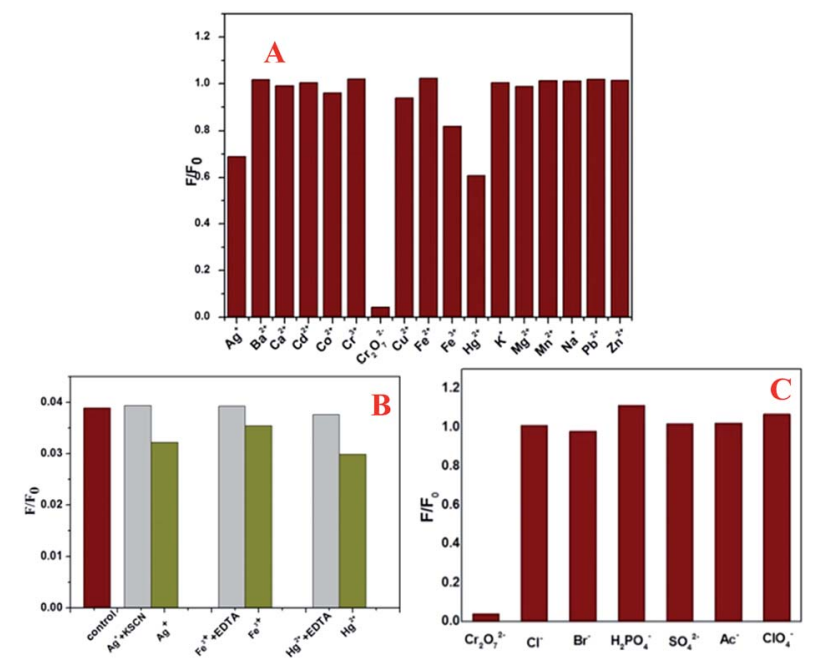

Fig. 5 (A) Fluorescence response of W-CDs in the presence of different metal ions, (B) the effect of KSCN and EDTA as masking reagent, (C) fluorescence response of $\mathrm{W}-\mathrm{CDs}$ in the presence of different common anions.

range of $0.05-100 \mu \mathrm{M}$ (Fig. 4 inset), where $F_{0}$ and $F$ are the FL intensity at $430 \mathrm{~nm}$ in the absence and presence of $\operatorname{Cr}(\mathrm{vI})$, respectively. The limit of detection (LOD) for $\mathrm{Cr}(\mathrm{vI})$ ions was estimated to be $16.8 \mathrm{nM}$ at a signal-to-noise ratio of 3. Similar with the W-CDs, the P-CDs could selectively detect the $\operatorname{Cr}(\mathrm{VI})$ ions in the range of $0.05-100 \mu \mathrm{M}$ as well, and the limit of detection for $\mathrm{Cr}(\mathrm{vI})$ was $29.6 \mathrm{nM}$ (Fig. $\mathrm{S} 7 \dagger$ ). The above results suggested that the CDs were robust and fast fluorescent probes for the detection of $\mathrm{Cr}(\mathrm{vI})$ in water.

To estimate the selectivity of CDs as a fluorescent probe, the effects of different kinds of competitive metal ions on the fluorescence were investigated, including $\mathrm{Na}^{+}, \mathrm{Ca}^{2+}, \mathrm{Cd}^{2+}, \mathrm{Cr}^{3+}$, $\mathrm{K}^{+}, \mathrm{Fe}^{3+}, \mathrm{Fe}^{2+}, \mathrm{Ag}^{+}, \mathrm{Mg}^{2+}, \mathrm{Ba}^{2+}, \mathrm{Zn}^{2+}, \mathrm{Cu}^{2+}, \mathrm{Pb}^{2+}, \mathrm{Mn}^{2+}, \mathrm{Co}^{2+}, \mathrm{Hg}^{2+}$ at a concentration of $500 \mu \mathrm{M}$. With the exception of $\mathrm{Fe}^{3+}, \mathrm{Ag}^{+}$ and $\mathrm{Hg}^{2+}$ cations, most of the metal ions including $\mathrm{Cr}^{3+}$ would not interfere the detection of $\mathrm{Cr}(\mathrm{vI})$ (Fig. 5A). We used KSCN as $\mathrm{Ag}^{+}$ions chelator and EDTA as $\mathrm{Fe}^{3+}$ and $\mathrm{Hg}^{2+}$ ion chelator to eliminate the interference of these cations to the detection of $\mathrm{Cr}(\mathrm{vI})$. As a result, the interference of the $\mathrm{Ag}^{+}, \mathrm{Fe}^{3+}$ and $\mathrm{Hg}^{2+}$ ions were negligible in the presence of KSCN and EDTA (Fig. 5B). $\mathrm{Cr}(\mathrm{vI})$ is anion $\left(\mathrm{CrO}_{4}{ }^{2-}\right.$ or $\left.\mathrm{Cr}_{2} \mathrm{O}_{7}{ }^{2-}\right)$ in water solution, so we also investigated the effect of some common anions. The results showed that $\mathrm{Ac}^{-}, \mathrm{SO}_{4}{ }^{2-}, \mathrm{Cl}^{-}$and $\mathrm{Br}^{-}$can not quench the fluorescence of the $\mathrm{W}$-CDs, $\mathrm{ClO}_{4}{ }^{-}$and $\mathrm{H}_{2} \mathrm{PO}_{4}{ }^{-}$even slightly enhance the fluorescence of the W-CDs at the concentration of $500 \mu \mathrm{M}$ (Fig. 5C). The P-CDs show the similar trend toward $\mathrm{Cr}(\mathrm{vI})$ as well (Fig. S8 $\dagger$ ). All these results clearly demonstrated that the present fluorescent sensor CDs exhibits high selectivity for the $\mathrm{Cr}(\mathrm{vI})$ detection in water environmental samples.

\section{Real samples testing}

The as-prepared CDs sensor was applied to the detection of $\mathrm{Cr}(\mathrm{vI})$ in real water samples by the standard addition analysis. The results were listed in Table 1 . The recovery of the added known amount of $\mathrm{Cr}(\mathrm{vI})$ ions to the three water samples was in 
Table 1 Determination of $\mathrm{Cr}(\mathrm{VI})$ ions in water samples

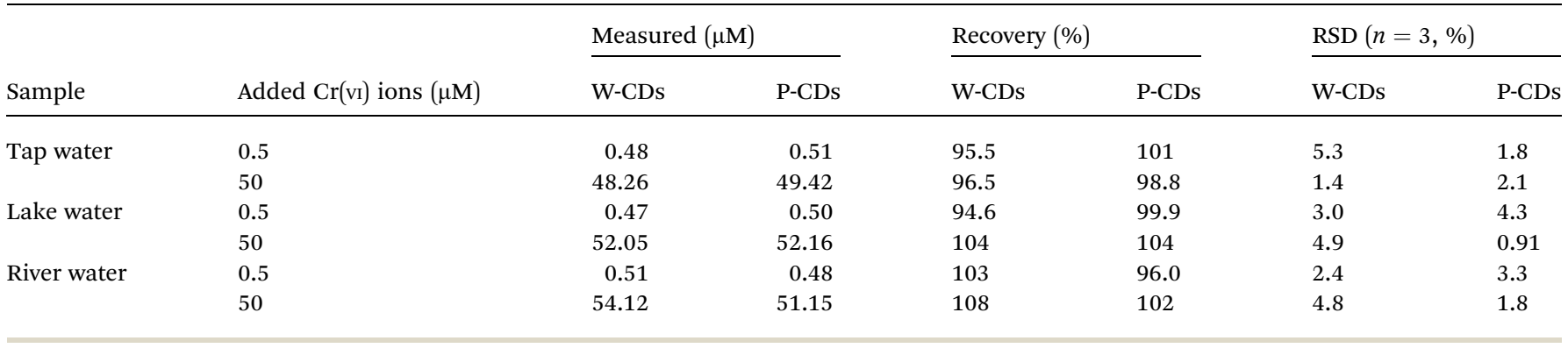

the range of $94.6-108 \%$ and $96.0-104 \%$, respectively; and the relative standard deviation (RSD) was in the range of $1.4-5.3 \%$ and $0.91-4.3 \%$, respectively, indicating the present CDs can be an excellent sensor for the direct determination of $\mathrm{Cr}(\mathrm{vI})$ for real samples analysis (Fig. 6).

\section{Possible mechanism of the FL quenching of CDs to $\mathrm{Cr}$ (vi)}

The fluorescence quenching of W-CDs and P-CDs to $\mathrm{Cr}(\mathrm{vI})$ is believed to be related to the formation of a new complex and fast electron transfer between $\mathrm{Cr}(\mathrm{vI})$ and CDs. According to the XPS results, the peak intensity of oxygen containing functional groups is different from that in carbon dots before the addition of $\mathrm{Cr}(\mathrm{VI})$. The ratio of the $-\mathrm{COOH}$ peak increased, the ratio of the $\mathrm{C}=\mathrm{O}$ peak decreased, and the $\mathrm{S} 2 \mathrm{p}$ band shifted to a high binding energy. These results are due to the fact that chromium might bind to groups containing oxygen, such as carboxyl or phenolic groups present on the surface of carbon dots, ${ }^{11}$ meanwhile, $\mathrm{Cr}(\mathrm{vI})$ adsorbed on the surface of CDs can coordinate with thiol groups on edges of CDs. The changes of the peaks are attributed to the reduction of the adsorbed $\mathrm{Cr}(\mathrm{vI})$ ions, with a simultaneous formation of additional carboxylic groups on the surface of carbon dots, which can act as binding sites for $\mathrm{Cr}(\mathrm{III}) .{ }^{12}$ Furthermore, the spectra of Cr were also detected. In pure $\mathrm{K}_{2} \mathrm{Cr}_{2} \mathrm{O}_{7}$, the peaks at 579.7 and $588.9 \mathrm{eV}$ were assigned to the $\operatorname{Cr} 2 \mathrm{p}_{1 / 2}$ and $\mathrm{Cr} 2 \mathrm{p}_{3 / 2}$ groups of $\mathrm{Cr}(\mathrm{vI})$, respectively. After
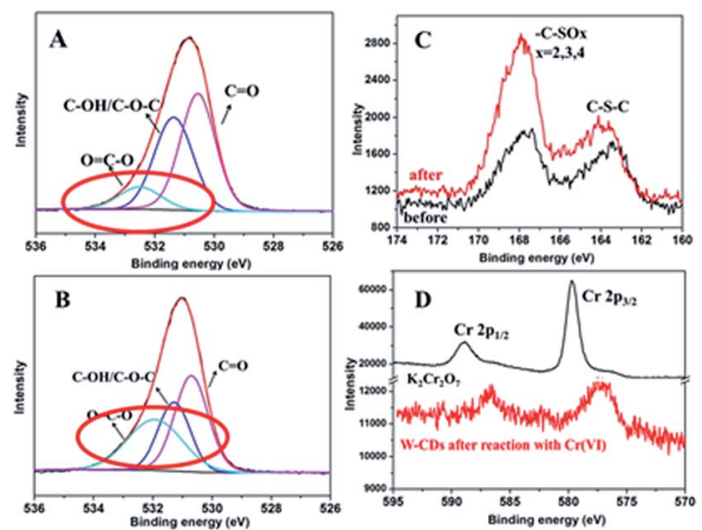

Fig. 6 High-resolution $O((A)$ before, (B) after), and S 2p (C) XPS spectra of $\mathrm{W}-\mathrm{CD}$ s before and after the addition of $\mathrm{Cr}(\mathrm{VI})$, the core-level lines of $\mathrm{Cr} 2 \mathrm{p}$ of pure $\mathrm{K}_{2} \mathrm{Cr}_{2} \mathrm{O}_{7}$ powder and $\mathrm{W}-\mathrm{CDs}$ after reaction with $\operatorname{Cr}(\mathrm{vI})(\mathrm{D})$ reaction with $\mathrm{W}$-CDs, the $\mathrm{Cr}$ element was detected on the surface of W-CDs. But, the peaks at 577.2 and $586.6 \mathrm{eV}$ were assigned to the groups of $\mathrm{Cr}(\mathrm{III}) .^{34,35}$ The presence of $\mathrm{Cr}(\mathrm{III})$ is thought to originate from the chemical interactions of $\mathrm{Cr}(\mathrm{vI})$ ions with carbon dots. This clearly demonstrates that oxidation-reduction reaction has occurred between $\mathrm{Cr}(\mathrm{vI})$ and $\mathrm{W}$ CDs, which generated electron transfer from the CDs to the $\mathrm{Cr}(\mathrm{vI})$ and led to nonradiative electron/hole recombination, resulting in the fluorescence quenching.

\section{Conclusions}

In summary, a green, simple, and low-cost hydrothermal method using wool and pig hair as the precursor has been developed to fabricate sulfur- and nitrogen-doped carbon dots for the first time. The precursors come from natural raw material, which are nontoxic and readily available. The obtained CDs have desirable functional groups attached to the particle surface and exhibit strong fluorescence emission, excellent $\mathrm{pH}$ stabilities and high ionic strength tolerance. The robust CDs exhibit high selectivity to $\mathrm{Cr}(\mathrm{vI})$ over most coexisting metal cations and anions. By employing this sensor, the quenching degree of the CDs is linearly proportional to the concentrations of $\mathrm{Cr}(\mathrm{vI})$ ions in a wide range of $50 \mathrm{nM}$ to $100 \mu \mathrm{M}$ and the detection limit is in the range of nM. In conclusion, the easily synthesized sulfur- and nitrogen-doped carbon dots can serve as a very efficient fluorescent sensor for the detection of $\operatorname{Cr}(\mathrm{vI})$.

\section{Acknowledgements}

This work was jointly supported by National Basic Research Program of China (2015CB932003), the National Natural Science Foundation of China (21537004, 21277152, 21277002, 21477140), and Strategic Priority Research Program of the Chinese Academy of Sciences (XDB14010201).

\section{Notes and references}

1 J. Johnson, L. Schewel and T. E. Graedel, Environ. Sci. Technol., 2006, 40, 7060-7069.

2 V. Arancibia, M. Valderrama, K. Silva and T. Tapia, J. Chromatogr. B: Anal. Technol. Biomed. Life Sci., 2003, 785, 303-309. 
3 Y. Xiang, L. Mei, N. Li and A. Tong, Anal. Chim. Acta, 2007, 581, 132-136.

4 R. Ouyang, S. A. Bragg, J. Q. Chambers and Z. L. Xue, Anal. Chim. Acta, 2012, 722, 1-7.

5 M. R. Moghadam, S. Dadfarnia and A. M. H. Shabani, J. Hazard. Mater., 2011, 186, 169-174.

6 M. Hosseini, V. K. Gupta, M. R. Ganjali, Z. Rafiei-Sarmazdeh, F. Faridbod, H. Goldooz, A. R. Badiei and P. Norouzi, Anal. Chim. Acta, 2012, 715, 80-85.

7 C.-X. Sui, Y.-F. Liu, W.-H. Zhang, P.-A. Li and D. Zhang, Microchim. Acta, 2013, 181, 347-353.

8 Y. Wang and A. Hu, J. Mater. Chem. C, 2014, 2, 6921.

9 H. Li, Z. Kang, Y. Liu and S.-T. Lee, J. Mater. Chem., 2012, 22, 24230.

10 H. Ding, J. S. Wei and H. M. Xiong, Nanoscale, 2014, 6, 13817-13823.

11 Y. Dong, H. Pang, H. B. Yang, C. Guo, J. Shao, Y. Chi, C. M. Li and T. Yu, Angew. Chem., Int. Ed. Engl., 2013, 52, 7800-7804.

12 J. Hou, J. Li, J. Sun, S. Ai and M. Wang, $R S C A d v$., 2014, 4, 37342 .

13 Z. X. Wang and S. N. Ding, Anal. Chem., 2014, 86, 7436-7445. 14 Y.-C. Lu, J. Chen, A.-J. Wang, N. Bao, J.-J. Feng, W. Wang and L. Shao, J. Mater. Chem. C, 2015, 3, 73-78.

15 S. Liu, J. Tian, L. Wang, Y. Zhang, X. Qin, Y. Luo, A. M. Asiri, A. O. Al-Youbi and X. Sun, Adv. Mater., 2012, 24, 2037-2041.

16 M. Algarra, B. B. Campos, K. Radotić, D. Mutavdžić, T. Bandosz, J. Jiménez-Jiménez, E. Rodriguez-Castellón and J. C. G. Esteves da Silva, J. Mater. Chem. A, 2014, 2, 8342.

17 Y. Liu, Y. Liu, S. J. Park, Y. Zhang, T. Kim, S. Chae, M. Park and H. Y. Kim, J. Mater. Chem. A, 2015, 3, 17747-17754.

18 W. J. Bai, H. Z. Zheng, Y. J. Long, X. J. Mao, M. Gao and L. Y. Zhang, Anal. Sci., 2011, 27, 243-246.
19 J. Wang, J. Wei, S. Su and J. Qiu, New J. Chem., 2015, 39, 501507.

20 K. Qu, J. Wang, J. Ren and X. Qu, Chem.-Eur. J., 2013, 19, 7243-7249.

21 P. Shen and Y. Xia, Anal. Chem., 2014, 86, 5323-5329.

22 P. M. Carrasco, I. García, L. Yate, R. Tena Zaera, G. Cabañero, H. J. Grande and V. Ruiz, Carbon, 2016, 109, 658-665.

23 T. Tian, Y. He, Y. Ge and G. Song, Sens. Actuators, B, 2017, 240, 1265-1271.

24 H. Y. Zhang, Y. Wang, S. Xiao, H. Wang, J. H. Wang and L. Feng, Biosens. Bioelectron., 2016, 87, 46-52.

25 L. Bu, J. Peng, H. Peng, S. Liu, H. Xiao, D. Liu, Z. Pan, Y. Chen, F. Chen and Y. He, RSC Adv., 2016, 6, 95469-95475.

26 P. C. Hsu, P. C. Chen, C. M. Ou, H. Y. Chang and H. T. Chang, J. Mater. Chem. B, 2013, 1, 1774-1781.

27 L. Wang and H. S. Zhou, Anal. Chem., 2014, 86, 8902-8905. 28 S. J. Zhao, M. H. Lan, X. Y. Zhu, H. T. Xue, T. W. Ng, X. M. Meng, C. S. Lee, P. F. Wang and W. J. Zhang, ACS Appl. Mater. Interfaces, 2015, 7, 17054-17060.

29 W. Li, Z. Yue, C. Wang, W. Zhang and G. Liu, RSC Adv., 2013, 3, 20662.

30 J. Zhou, Z. Sheng, H. Han, M. Zou and C. Li, Mater. Lett., 2012, 66, 222-224.

31 X. M. Yang, Y. Zhuo, S. S. Zhu, Y. W. Luo, Y. J. Feng and Y. Dou, Biosens. Bioelectron., 2014, 60, 292-298.

32 D. Sun, R. Ban, P.-H. Zhang, G.-H. Wu, J.-R. Zhang and J.-J. Zhu, Carbon, 2013, 64, 424-434.

33 L. Li, G. Wu, T. Hong, Z. Yin, D. Sun, E. S. Abdel-Halim and J. J. Zhu, ACS Appl. Mater. Interfaces, 2014, 6, 2858-2864.

34 Y. Lei, F. Chen, Y. Luo and L. Zhang, J. Mater. Sci., 2014, 49, 4236-4245.

35 L. Zhang, C. Xu and B. Li, Microchim. Acta, 2009, 166, 61-68. 